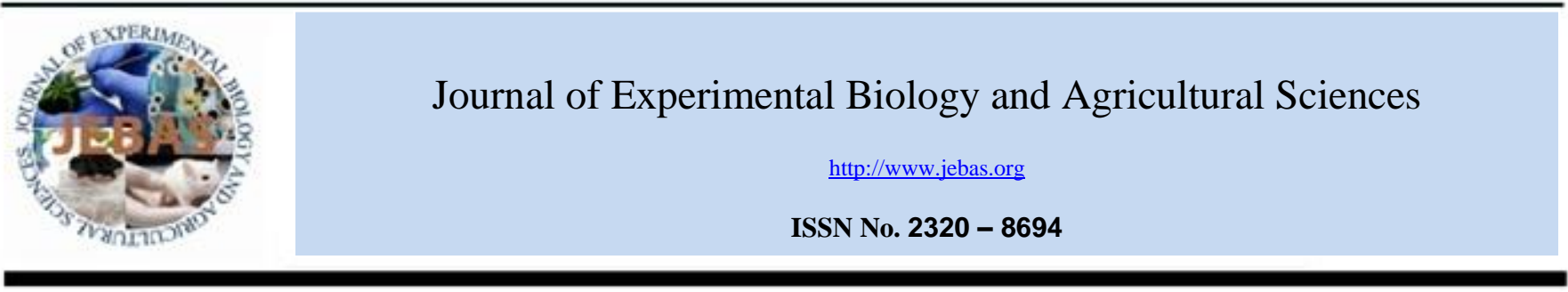

\title{
DETECTION OF QUANTITATIVE TRAIT LOCI (qtl) ASSOCIATED WITH YIELD AND YIELD COMPONENT TRAITS IN SORGHUM [Sorghum bicolor (L.) Moench] SOWN EARLY AND LATE PLANTING DATES
}

\author{
Zenbaba Gutema ${ }^{1, *}$, Teshale Assefa ${ }^{2}$ and Fuyou $\mathrm{Fu}^{3}$
}

\author{
${ }^{1}$ Department of Biology, Northern Virginia Community College, Annandale Campus, 8333 Little River Turnpike, Annandale, VA 22003 \\ ${ }^{2}$ Department of Agriculture, Iowa State University, 2104 Agronomy Hall, Ames, Iowa, USA \\ ${ }^{3}$ Department of Agronomy, Purdue University, 915 W. State Street, West Lafayette, USA
}

Received - October 25, 2015; Revision - November 08, 2015; Accepted - January 27, 2016

Available Online - February 15, 2016

DOI: http://dx.doi.org/10.18006/2015.4(1).26.36

KEYWORDS
QTL
DArT
Yield and yield components
Planting dates
Sorghum

* Corresponding author

E-mail: zwordoffa@nvcc.edu (Zenbaba Gutema)

Peer review under responsibility of Journal of Experimental Biology and Agricultural Sciences.

Production and Hosting by Horizon Publisher (http://publisher.jebas.org/index.html).

All rights reserved.

\begin{abstract}
Genetic improvement for grain yield is one of the challenges in plant breeding programs. QTL analysis is often used to dissect complex trait like grain yield for a better genetic manipulation. The purpose of this study was to map QTLs associated with yield and yield component traits of sorghum grown under early and late planting dates. A total of 528 recombinant inbred lines (RILs) and their two parents were sown early and late planting times in an augmented rectangular lattice block design with two replications to generate field phenotypic data. A total of 379 markers consisting of DArT, SSR and morphological markers were used to genotype the RILs and the parents. Results revealed the presence of overall twelve QTL across traits and planting dates. More QTLs were detected for grain yield as compared to each of the other traits and most QTL associated with grain yield were consistent across planting dates while QTL associated with yield component traits were not. Stable QTLs detected in this study might provide valuable information in breeding sorghum for enhanced grain yield in diverse growing environment.
\end{abstract}

All the article published by Journal of Experimental Biology and Agricultural Sciences is licensed under a Creative Commons Attribution-NonCommercial 4.0 International License Based on a work at www.jebas.org.

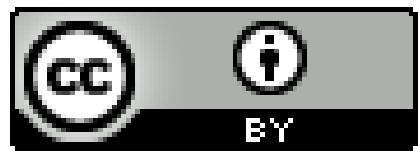




\section{Introduction}

Grain yield genetic improvement is one of the most important objectives of many plant breeding programs around the world. However, grain yield genetic manipulation has remained to be a continued challenge in crop breeding. Sorghum [Sorghum bicolor (L.) Moench] is the fifth most important cereal crop in the world (FAO, 2012). It is the staple food for millions of people in Africa and Asia. It is also one of the major feed crops in the developed countries. Sorghum is extensively grown in arid and semi-arid tropical and subtropical regions of the world (Doggett, 1988). Sorghum cultivation has also been expanded to the wet, cool temperate regions of the world particularly in North America. Despite its economic importance, however, sorghum has not been characterized very well genetically.

The multiplicative and interactive nature among yield components in the formation of sorghum grain yield makes the genetic manipulation of this important trait more complex (Francis et al., 1983; Heinrich et al.,1985; Saeed et al., 1986). Quantitative trait loci (QTL) analysis approach is useful in dissecting such a complex trait for a better genetic manipulation. QTLs linked with robust molecular markers could be used to increase the efficiency of selection and genetic gain in grain yield improvement.

QTL analysis has been used to detect genomic regions and QTL associated with grain yield and its component for some other crop species (Lu et al., 1997; Lu et al., 2006; Liu et al., 2008; Xue et al., 2010). In sorghum, QTL associated with yield and yield component traits have been reported recently (Shehzad \& Okuno, 2015). Further, a number of QTLs have been also reported recently under certain contrasting conditions such as photoperiod (Zou et al., 2012) and drought adaptation (Phuong et al., 2013; Borrell et al., 2014) but till now, planting dates have not been considered in QTL analysis. Although in general late planting is considered normal, farmers desire early planting because of its several advantages including full utilization of late spring and early summer rainfalls. Early planting may also help in completing plant life cycle before cold spell during the growing season (Yu \& Tuinstra, 2001). Most of the current sorghum cultivars are developed under late planting, however, early planting needs to be considered as well.

In the present study, large numbers of molecular and field data were generated on grain yield and its component traits like plant population, kernel number and kernel weight by using RIL population sown early and late planting dates. The data were subjected to QTL analyses utilizing relatively dense genetic map constructed from mix of molecular and morphological markers. Several QTL were detected segregating in this large population for each of the traits. However, only few QTL were found to be stable across planting dates. These stable QTL were listed and characterized for further studies targeting sorghum breeding for better grain yield.

\section{Materials and Methods}

\subsection{Genetic materials and experimental design}

Sorghum recombinant inbredlines (RILs) lines were derived from a cross between SRN-39 (an African caudatum) and Shan Qui Red (SQR), (a Chinese germplasm line). The two parents differ for a number of characteristics including yield and yield components. About 1000 random $\mathrm{F}_{2}$ plants of this cross were selfed and advanced up to the $\mathrm{F}_{5}$ generation by the single seed descent method. Selfed seeds from each inbred line were used to grow $\mathrm{F}_{5: 6}$ progeny rows which were selfed and bulked (Cisse \& Ejeta 2003). Subsequent generations were maintained through repeated cycles of selfing and bulking to $F_{5: 9}$ seeds from which a total of 528 RI lines were sampled for the purpose of this study. Seeds of these parents were maintained in the on-going sorghum breeding nurseries.

The RILs and the parents were grown in an augmented lattice design with 24 sub-blocks within two replications. The parents were repeated in each sub-block thus each replication constituted 576 total entries each with a two-row plot. Rows of six meter length, spaced $75 \mathrm{~cm}$ apart were drill-seeded at the rate of approximately 10 seeds per $30 \mathrm{~cm}$ at a depth of $2.5 \mathrm{~cm}$ by a John Deer Max Emerge planter modified for small research plots. The seedlings were hand-thinned to a spacing of 6 plants per $30 \mathrm{~cm}$. The nurseries were planted during the 2005 and 2006 crop seasons at Purdue University Agronomy Center for Research and Education (ACRE) in West Lafayette, Indiana. The nurseries were planted early and late planting dates each year. The first planting dates were at least three weeks earlier than the late (normal) planting and they were chosen to enhance performance differences among the RILs under cool and wet soil conditions. Relatively large data were generated for QTL analysis on sorghum grain yield and yield components. Three yield components: plant population size, kernel number, and kernel weight were assessed.

Weather conditions were measured at hourly intervals via a weather station close to the test plots. Weather data during the early and late planting dates of the experiments are summarized in Table 1 . The weather conditions were contrasting between early and late planting dates especially during the early growing period (times during seedling growth) of the nursery. The average rainfall was lower in 2005 than in 2006. 
Table 1 Climatic condition of study site at Purdue University Agronomy Center for Research and Education, West Lafayette, Indiana in 2005 and 2006 crop seasons.

\begin{tabular}{|l|c|c|c|c|c|c|}
\hline \multirow{2}{*}{ Planting time } & Planting Date & \multicolumn{4}{|c|}{ Temperature $\left.{ }^{0} \mathrm{C}\right)$} & Rainfall (mm) \\
\cline { 3 - 6 } & & \multicolumn{2}{|c|}{ Soil } & \multicolumn{2}{|c|}{ Air } & \\
\cline { 3 - 6 } & & Min & Max & Min & Max & Average \\
\hline Early & May 4, 2005 & 11.9 & 20.0 & 9.3 & 20.8 & 54.1 \\
\hline Late & May 23, 2005 & 19.2 & 28.1 & 18.0 & 26.0 & 61.5 \\
\hline Early & April 27, 2006 & 9.6 & 26.0 & 6.3 & 26.9 & 89.4 \\
\hline Late & May 30, 2006 & 19.7 & 28.3 & 18.3 & 27.3 & 86.0 \\
\hline
\end{tabular}

Data courtesy of Purdue University Weather Station.

\subsection{Phenotypic data measurements and analyses}

The middle five meters of the two rows in each of the RILs entries were used for yield and yield component traits measurements in this study. Plants per plot $\left(3.75 \mathrm{~m}^{2}\right)$ were counted at maturity to determine plant population size. Panicles of counted plants were harvested manually at the end of the growing season for each plot, threshed and weighed for grain yield ( $\mathrm{kg} / \mathrm{plot})$ for QTL analyses but converted to $\mathrm{t} / \mathrm{ha}$ for analyses of variance (ANOVA), which was used to examine significant differences among the RILs for these traits. One hundred counted seed weights were measured and kernel number per plant was estimated from data on kernel weight, grain yield and number of plants per plot. Values were averaged per replication for each of the traits for QTL analyses.

The ANOVA was carried out using GLM procedure in SAS V. 9.1 (SAS Institute, Cary, NC) using the following general model: $\mathrm{Y}=\mathrm{g}+\mathrm{G}+\mathrm{L}(\mathrm{R})+\varepsilon$, (Knoll \& Ejeta, 2008) where $\mathrm{Y}$ is the dependent variable, $\mu$ is the experiment mean, $\mathrm{G}$ is a genotypic effect, $\mathrm{R}$ is a replicate, $\mathrm{L}$ is a lattice block (nested in rep), and $\varepsilon$ is the error. Broad sense heritability was estimated following method of Cisse \& Ejeta (2003).

\subsection{Genomic DNA isolation}

Leaf tissue for genomic DNA isolation was harvested from field grown seedlings at three weeks after planting. Approximately one gram sections were cut from the uppermost second and third leaves and bulked. Harvested leaf tissue was kept on ice during harvest and lyophilized upon returning to the laboratory. The lyophilized samples were kept at $-80^{\circ} \mathrm{C}$ until grinding to a fine powder with a UDY Cyclone Mill. A CTAB based DNA extraction method according to SaghaiMaroof et al. (1984) was used with only minor modifications.

\subsection{Genotyping}

The 528 RILs and the two lines were genotyped with three types of markers vise-a-vise morphological markers scored in the field or laboratory, SSR markers scored in our laboratory and Diversity Array Technology (DArT ${ }^{\mathrm{TM}}$ ) markers scored at DArT Plc., Yarralumla, Australia. A total of 359 DArT ${ }^{\mathrm{TM}}$ markers that were polymorphic between the parents, 15 SSR markers and five morphological markers (seedling color, plant color, seed color, presence/absence of a pigmented testa layer and pericarp color) were used to construct a dense sorghum genetic linkage map using the maximum likelihood method of Join tMap 4 (Van Oijen, 2006).

\subsection{QTL analysis}

Single-trait analyses were undertaken for each environment data using composite interval mapping (CIM) (Zeng, 1994) with QTL Cartographer version 1.17ji (Basten et al., 2005). The CIM was undertaken with conditional settings of $10 \mathrm{cM}$ (default) control intervals, five control markers set by QTL Cartographer stepwise regression and forward/background (FB) stepwise regression to account for the genetic background variation. The five most significant (default) markers were utilized and the default threshold level of 2.5 LOD in QTL Cartographer 1.17ji (Basten et al., 2005) was used to declare a QTL.

\section{Results}

\subsection{Linkage map construction}

A genetic linkage map consisting 11 linkage groups was constructed in which chromosome A was found to be broken into two linkage groups according to Bhattramakki et al. (2000). We used SSR markers from this published map to anchor the relatively new DArT markers. The map spans 1175 $\mathrm{cM}$ with an average marker distance of $3.14 \mathrm{cM}$ with no major gap.

\subsection{Parental lines phenotypic analysis}

The parental lines displayed significant divergence for all the traits except for grain yield (Table 2). The SQR parent had more plants per plot as compared to SRN-39 under early cold planting. On the other hand, SRN-39 had better field establishment under late planting as expected for this Africa originated cultivar adapted to higher temperatures. However, it did not exceed the SQR even under improved temperatures, suggesting the importance of SQR for field establishment under any planting condition. Contrary to plant population, SRN-39 had more kernels as compared to SQR under both early and late plantings. 
Table 2 Summarized mean performance of parental lines in field experiments planted early and late during 2005 and 2006 crop seasons at the Agronomy Center for Research and Education testing site of Purdue University, West Lafayette, Indiana.

\begin{tabular}{|c|c|c|c|c|c|}
\hline \multirow[t]{2}{*}{ Planting time } & \multirow[t]{2}{*}{ Parental line } & \multicolumn{4}{|c|}{ Trait $^{\mathrm{a}}$} \\
\hline & & $\begin{array}{l}\text { Plant population } \\
\text { (count) }\end{array}$ & Kernel number & $\begin{array}{l}\text { Kernel weight } \\
(\mathrm{gm})\end{array}$ & Grain yield (t/ha) \\
\hline \multirow[t]{2}{*}{ Early } & SRN-39 & $24.08 \pm 10.3$ & $2699.49 \pm 120$ & $3.71 \pm 0.3$ & $4.31 \pm 0.8$ \\
\hline & SQR & $44.37 \pm 4.2$ & $1584.00 \pm 70$ & $2.84 \pm 0.4$ & $5.21 \pm 0.4$ \\
\hline \multirow[t]{2}{*}{ Late } & SRN-39 & $32.23 \pm 6.2$ & $1622.64 \pm 60$ & $3.75 \pm 0.2$ & $5.11 \pm 0.3$ \\
\hline & SQR & $43.05 \pm 3.2$ & $1521.01 \pm 45$ & $2.86 \pm 0.3$ & $4.46 \pm 0.2$ \\
\hline \multirow[t]{2}{*}{ Overall mean } & SRN-39 & $28.16 \pm 8.2$ & $2161.07 \pm 90$ & $3.73 \pm 0.3$ & $4.71 \pm 0.7$ \\
\hline & SQR & $43.71 \pm 4.0$ & $1552.51 \pm 65$ & $2.85 \pm 0.4$ & $4.84 \pm 0.3$ \\
\hline
\end{tabular}

a/Traits measured in augmented rectangular lattice block design with the parents repeated in each of 24 lattice blocks replicated twice in four field experiments conducted over two years.

SRN-39'salso had heavier kernels than SQR under both planting dates. The result of higher kernel number by SRN-39 under early planting as compared to $\mathrm{SQR}$ when it planted under late normal planting was probably in response to sparse plant population under cold early planting that killed some of its seedlings. Kernel weight was not significantly different in the planting dates for this parent. SQR yielded more grain than SRN-39 under early planting but not under late planting. Overall, SQR had higher yield than SRN-39 despite of SRN39's outperformance both in kernel number and kernel weight. The results might be a reflection of higher impact of plant population size on the development of grain yield in sorghum as compared to kernel number or kernel weight.

\subsection{Phenotypic analysis and broad-sense heritability}

Results in Table 3 showed wide variations and transgressive segregations for all traits among the RILs at both early and late planting dates. Phenotypic mean values for grain yield and other traits in this RIL population appeared to be more or less normally distributed (Figure 1). Mean agronomic performances were lower than each parent except for plant population trait where the RILs mean performance was higher than the 'low' parent SRN-39. The results indicated the extreme sensitivity of the African origin SRN-39 parent to cold weather andlor the efficiency of cold tolerance genes from Chinese highland SQR parent.

The RILs had better performance under late (normal) plantings for plant population size as well as grain yield traits as expected. However, for kernel number, on average, RILs had better performance under early plantings like the parents. For kernel weight, similar performance was observed across planting times although lower kernel weight was measured for 2006 late planted nursery. In general, mean agronomic performances of the RILs were better during 2005 crop season as compared to 2006. The air and soil temperatures during 2005 plantings improved quickly resulting into higher performance across planting dates during this season. In contrary, continued colder weather in 2006 crop season plantings killed seedlings of several entries particularly in early planted nursery and resulted into erratic field establishment which in turn resulted into lower agronomic performances for most traits. The highest overall mean agronomic performance was noted for 2005 late planted nursery, while the lowest was noted for 2006 early planted nursery, reflecting two possible extreme growing conditions for sorghum in our study. Overall, high standard deviations were recorded for all the traits except for kernel weight.

Table 3 Mean agronomic performance, range and heritability values of yield and yield component traits of sorghum measured in 528 RILs planted early and late cropping season.

\begin{tabular}{|l|c|c|c|c|c|}
\hline Year & Planting time & \multicolumn{4}{|c|}{ Trait $^{\text {a }}$} \\
\hline & & Plant population (count) & Kernel number & Kernel weight (gm) & Grain yield (t/ha) \\
\hline \multirow{2}{*}{2005} & Early & $40.7 \pm 13.1$ & $1257.5 \pm 47$ & $3.0 \pm 0.4$ & $3.7 \pm 1.1$ \\
\cline { 2 - 6 } & Late & $43.9 \pm 10.6$ & $1210.9 \pm 45$ & $3.1 \pm 0.5$ & $4.1 \pm 1.3$ \\
\hline \multirow{2}{*}{2006} & Early & $17.6 \pm 9.8$ & $2171.7 \pm 1120$ & $3.0 \pm 0.4$ & $2.7 \pm 1.4$ \\
\cline { 2 - 6 } & Late & $36.0 \pm 7.8$ & $1297.2 \pm 40$ & $2.8 \pm 0.4$ & $3.4 \pm 1.1$ \\
\hline Mean \pm Stdev $^{b}$ & & $34.6 \pm 15.0$ & $1484 \pm 789.2$ & $2.3 \pm 0.4$ & $3.5 \pm 1.3$ \\
\hline Range & & $1.0-78.0$ & $39.7-9102.1$ & $1.3-4.7$ & $0.004-7.7$ \\
\hline Heritability $\left(\mathrm{H}^{2}\right)$ & & 0.64 & 0.68 & 0.93 & 0.77 \\
\hline
\end{tabular}

${ }^{\mathrm{a}}$ Traits measured in augmented rectangular lattice block design with 24 lattice blocks replicated twice in four field experiments conducted over two years. ${ }^{\mathrm{b}} \mathrm{Stdev}=$ Standard deviation. 
Broad-sense heritability values were in general high and the high values illustrate the utility of this large RILs population in our study in determining greater genetic influence on the expression of traits as compared to the environment. The highest heritability value was calculated for kernel weight (0.93), followed by grain yield (0.77). Kernel number (0.68) and plant population (0.64) had relatively low heritability indicating more environmental influence in the expression of these two traits of present study.
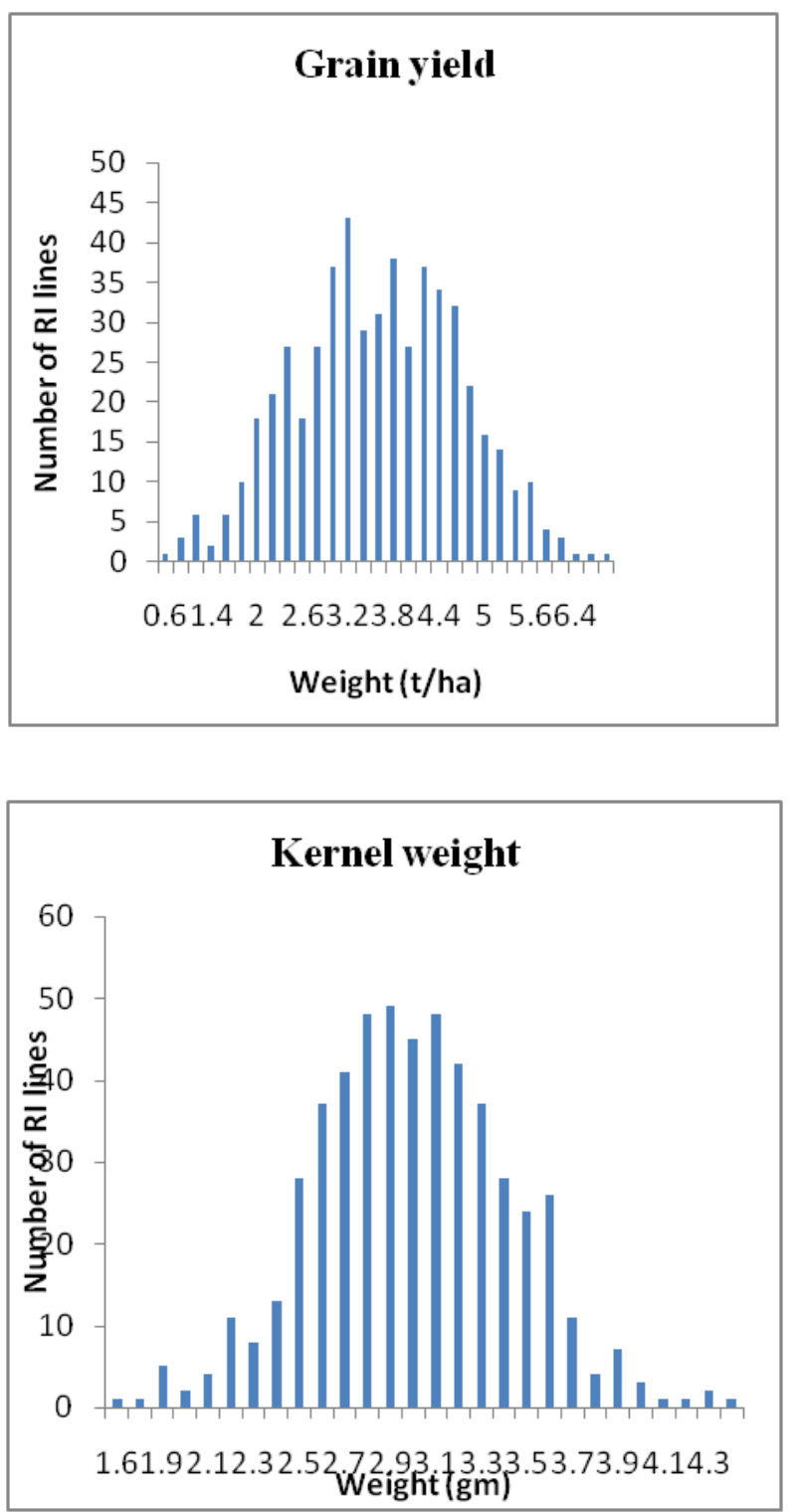

The ANOVA showed that there was highly significant variation for entries in each of the two years experiment for all the traits (Table 4). Planting date also had a significant effect. Furthermore, the interaction of planting date with the RI lines was highly significant in both years showing high genotypeby-environment interaction. The observed high phenotypic variability of all the traits in terms of ranges and ANOVA results indicated that the population was suitable for QTL analyses.
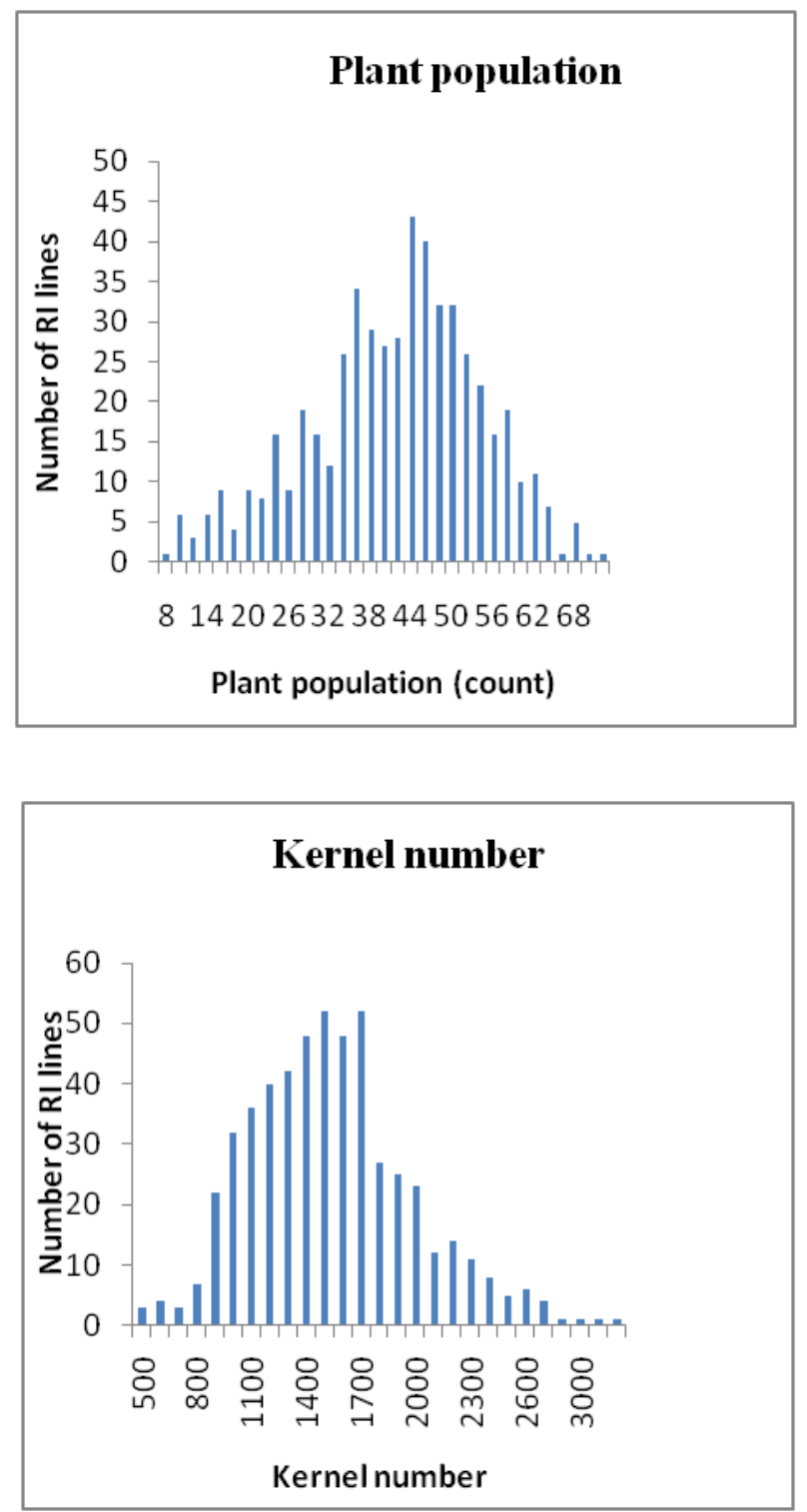

Figure 1 Phenotypic value distribution for 528 RILs planted in an augmented rectangular lattice design with 24 lattice blocks replicated twice in four field experiments conducted over two years. 
Table 4 Analysis of variance for grain yield and yield component traits of sorghum.

\begin{tabular}{|l|l|c|c|c|c|c|}
\hline Year & Source & $\mathbf{d f}^{\mathrm{a}}$ & $\begin{array}{c}\text { Plant } \\
\text { Population }^{\mathrm{b}}\end{array}$ & $\begin{array}{c}\text { Kernel } \\
\text { number }^{\mathbf{b}}\end{array}$ & $\begin{array}{c}\text { Kernel } \\
\text { weight }\end{array}$ & $\begin{array}{c}\text { Grain } \\
\text { yield }\end{array}$ \\
\hline 2005 & Planting Date & 1 & 43.558 & 0.218 & 15.281 & 5.297 \\
\hline & Rep(Planting Date) & 2 & 0.891 & 0.134 & 0.339 & 0.219 \\
\hline & Lattice block (Planting date x Rep) & 92 & 0.388 & 0.027 & 0.029 & 0.058 \\
\hline & RIL & 526 & 2.854 & 0.067 & 0.665 & 0.289 \\
\hline & Planting Date x RIL & 526 & 0.299 & 0.013 & 0.035 & 0.045 \\
\hline & Error & 960 & 0.152 & 0.007 & 0.019 & 0.021 \\
\hline 2006 & Planting Date & 1 & 1991.5 & 19.944 & 22.226 & 31.31 \\
\hline & Rep (Planting Date) & 2 & 16.856 & 1.671 & 0.028 & 0.725 \\
\hline & Lattice block (Planting date x Rep) & 92 & 0.531 & 0.028 & 0.025 & 0.053 \\
\hline & RIL & 526 & 2.307 & 0.091 & 0.547 & 0.399 \\
\hline & Planting Date x RIL & 526 & 0.824 & 0.028 & 0.035 & 0.090 \\
\hline & Error & 960 & 0.182 & 0.011 & 0.015 & 0.030 \\
\hline
\end{tabular}

${ }^{\mathrm{a}}$ Degrees of freedom. ${ }^{\mathrm{b}}$ Error variances for plant population and kernel number were not strictly homogenous in this analysis. $* * *$, All mean squares are significant at $\alpha=0.0001$.

\subsection{Phenotypic correlation among traits}

Pearson correlation coefficients were computed among traits values (Table 5). The largest but negative sign correlation coefficient $(\mathrm{r}=0.57)$ was observed between plant population and kernel number, the negative sign of the coefficient suggesting the opposing effect of these two traits in the formation of final grain yield in sorghum. The second largest but with positive sign of correlation coefficient $(\mathrm{r}=0.51)$ was between plant population and grain yield, indicating positive impact of plant population on grain yield of sorghum.

The other negative coefficient $(\mathrm{r}=0.26)$ was observed between plant population and kernel weight, again indicating the opposing effect of these two traits in the formation of sorghum grain yield. Significant positive correlations coefficients were also observed for both kernel number and kernel weight with grain yield. These results were as expected as both of these traits actually contribute to the measure of grain yield. Interestingly, kernel number and weight also had a positive correlation.

\subsection{QTL detection}

Sixteen data sets were organized and analyzed for QTL detection. Using the default 2.5 LOD threshold to declare a QTL in QTL Cartographer, a total of 12 QTL were detected across traits and planting dates as summarized in Table 6 . Seven chromosomes (linkage groups) of the ten sorghum chromosomes were mapped with one or more QTL (Figure 2). Twenty two DArT and two SSR markers were closely linked with QTLs of the traits (Table 7). Compared planting time wise, in general, the number of QTL detected tended to be higher in late (normal) planted nurseries as compared to early planted nurseries.

\subsection{Plant population}

Two QTLs were detected for plant population (Table 6). These QTL were detected in both early and late planted nurseries of 2005 crop season but no QTL detected for plant population in our extended cold season experiments of 2006 where cold had significant impact on seedling establishment. The phenotypic variation explained by these QTLs ranged from two to three percent and the additive effects for both QTL were 3.2. The increasing alleles of the QTLs expressed under early planting time was contributed by the Chinese cold tolerant SQR line while the alleles for QTLs expressed under late planting contributed by African originated SRN-39 genotype both of these results being as expected.

\subsection{Kernel number}

Three QTL were detected for kernel number across planting dates and years (Table 6). Unlike in plant population trait, two QTLs were detected in severe cold conditions of 2006 early planted nursery. From phenotypic data analysis, kernel number trait performance was best in this nursery and the result might suggest the importance of good phenotypic performance in the detection of more QTL. The phenotypic variations explained by the QTLs were four percent and were the same for all the QTL. The additive effects were103 and 227 for alleles contributed by the parent SRN-39 and 159 for alleles contributed by the parent $\mathrm{SQR}$.

\subsection{Kernel weight}

Like in plant population, only two QTLs were detected with the default 2.5 LOD threshold used for other traits but with slight modification of this threshold to 2.4, four more QTLs were detected for kernel weight (data not shown). 
Table 5 Pearson correlation coefficients (R) among yield and yield component traits values from data on 528 RI lines replicated twice in four field experiments conducted over two years.

\begin{tabular}{|c|c|c|c|c|}
\hline Traits & Plant population & Grain yield & Kernel weight & Kernel number \\
\hline Plant population & 1.00 & & & \\
\hline Grain yield & $0.51 * * *$ & 1.00 & & \\
\hline Kernel weight & $-0.26 * * *$ & $0.10^{* * *}$ & 1.00 & \\
\hline Kernel number & $-0.57 * * *$ & $0.15^{* * *}$ & $0.10 * * *$ & 1.00 \\
\hline
\end{tabular}

$* * *$, Significant at $\alpha=0.0001$.

Table 6 Number of QTL detected with data collected early and late (normal) planted nurseries for grain yield and yield component traits of sorghum as analyzed through composite interval mapping (CIM).

\begin{tabular}{|lllcccc|}
\hline \multirow{2}{*}{ Year } & Planting Date & \multicolumn{4}{c|}{ Number of QTL detected } & Total \\
\cline { 3 - 7 } & & Plant population & Kernel number & Kernel weight & Grain yield \\
\hline \multirow{2}{*}{2005} & Early & 1 & - & - & 2 & 3 \\
& Late & 1 & 1 & - & 1 & 3 \\
\hline \multirow{2}{2006}{} & Early & - & 2 & - & - & 2 \\
& Late & - & - & 2 & 2 & 4 \\
\hline Total & & 2 & 3 & 2 & 5 & 12 \\
\hline
\end{tabular}

Despite similar phenotypic performance of kernel weight trait across most of our environments, QTLs detected for kernel weight were limited to 2006 late planted nursery. Both parents contributed to the increasing alleles.

\subsection{Grain yield}

A total of five QTLs were detected for grain yield although from the partially overlapping position three QTLs seemed to be the same. No QTL detected for grain yield in 2006 cold early planted nursery in a manner this environment affected QTL detection for plant population. From phenotypic data analysis, plant population has significant impact on grain yield which might have again reflected on the detection of QTL for grain yield in this environment. Three QTLs were detected in three of four environments indicating the most consistence of grain yield QTL in this study. Two of the QTL were found on two different chromosomes (C and E) but three QTLs were all found on the same chromosome (F). A LOD score as high as 4.5 were noted for one of these QTL showing high evidence for grain yield QTLs in our analysis. The phenotypic variations explained by the QTL ranged from two to five. Unlike yield component traits where both parents contributed the increasing alleles, all the increasing alleles were contributed by SRN-39 for grain yield.

\section{Discussion}

\subsection{Phenotypic traits analysis}

Traits from seedling to crop maturity can impact grain yield of sorghum (Heinrich et al., 1985; Saeed et al., 1986). Present study shows that plant population (density) is the most important trait among yield component traits of sorghum to increase grain yield per unit area. The far reaching importance of plant population sizes in grain yield per unit area was recognized for maize long ago (Tokatlidis \& Koutroubas 2004). In sorghum, the importance of plant population size might be overlooked because sorghum plants try to compensate grain yield loss due to sparse population by tillering (Stickler \& Pauli, 1961). Observation on parental lines demonstrated this assertion. We observed that SRN-39 responded to sparse population by tillering and producing more and heavier kernels, but surprisingly it did not produce higher grain yield than SQR. Clearly, SQR produced more plant population per unit area than SRN-39, which resulted into higher grain yield. The results indicated the importance of plant population for increasing grain yield in sorghum, especially under cold early planting. Furthermore, our RILs correlation analyses show that plant population is positively and highly correlated with grain yield, suggesting that an increase in plant population per unit area would results into an increase in grain yield as well. On the other hand, it was observed that plant population is negatively correlated with other yield components such as kernel number and kernel weight. This result suggested the counter effect of increased plant population on grain yield through these two yield component traits. As the number of plants per plot increases, smaller panicles (thus fewer kernel number/panicle) with smaller kernel size (thus lesser kernel weight) are produced because of plant to plant competition. Therefore, optimum plant population (density) should be established by empirical field data to maximize grain yield for a given cultivar under a given production condition (Francis et al., 1983). 

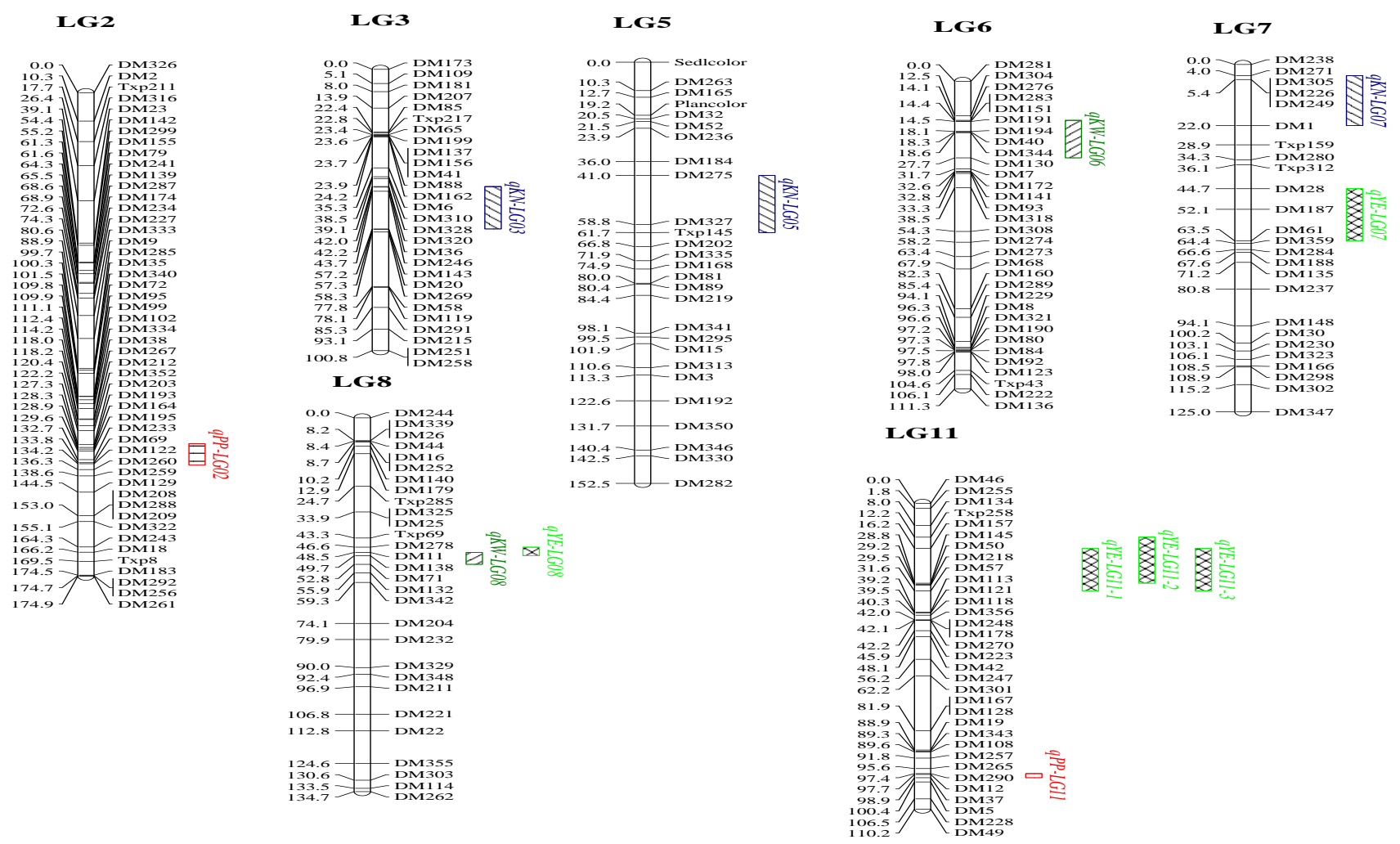

Figure 2 Genetic linkage map showing significant QTL associated with grain yield and yield component traits of 528 RIL and their parents grown early and late planting dates.QTL named as q=QTL, followed by abbreviation name of the trait: YE=grain yield, $\mathrm{KN}=$ kernel number, $\mathrm{KW}=$ kernel weight and $\mathrm{PP}=$ plant population, and linkage group number (LG) and then serial number of the QTL per linkage group.

Table 7 List of QTL mapped for plant population, kernel number, kernel weight and grain yield analyzed using CIM.

\begin{tabular}{|c|c|c|c|c|c|c|c|}
\hline Trait & QTL $^{\mathrm{a}}$ & Flanking marker & Position $^{c}$ & Additive effect & $\mathrm{R}^{2 \mathrm{~d}}(\%)$ & LOD score & Source $^{e}$ \\
\hline \multirow[t]{2}{*}{ Plant population } & qPP-LG02 & DM164-DM233 & 130 & 3.24 & 3 & 3.0 & SQR \\
\hline & qPP-LG11 & DM290-DM37 & 99 & 3.16 & 2 & 2.7 & SRN-39 \\
\hline \multirow[t]{3}{*}{ Kernel number } & qKN-LG03 & DM320-DM143 & 50 & 159 & 4 & 3.3 & SQR \\
\hline & qKN-LG05 & DM275-Txp145 & 46 & 227 & 4 & 3.5 & SRN-39 \\
\hline & qKN-LG07 & DM271-DM1 & 13 & 103 & 4 & 3.4 & SRN-39 \\
\hline \multirow[t]{2}{*}{ Kernel weight } & qKN-LG06 & DM276-DM130 & 22 & 0.10 & 3 & 3.3 & SRN-39 \\
\hline & qKN-LG08 & DM11-DM71 & 50 & 0.08 & 3 & 2.7 & SQR \\
\hline \multirow[t]{5}{*}{ Grain yield } & qYE-LG07 & DM28-DM61 & 50 & 0.23 & 4 & 3.4 & SRN-39 \\
\hline & qYE-LG08 & DM278-DM138 & 45 & 0.22 & 5 & 3.6 & SRN-39 \\
\hline & qYE-LG11-1 & DM157-DM57 & 30 & 0.32 & 5 & 4.5 & SRN-39 \\
\hline & qYE-LG11-2 & Txp258-DM145 & 15 & 0.16 & 4 & 3.5 & SRN-39 \\
\hline & qYE-LG11-3 & DM157-DM57 & 22 & 0.14 & 2 & 2.6 & SRN-39 \\
\hline
\end{tabular}

${ }^{a}$ QTL named as $q=Q T L$, followed by abbreviation name of the trait: $\mathrm{YE}=$ grain yield, $\mathrm{KN}=$ kernel number, $\mathrm{KW}=\mathrm{kernel}$ weight and $\mathrm{PP}=$ plant population, linkage group number (LG) and serial number of the QTL per linkage group. ${ }^{\mathrm{b}}$ Left and right flanking markers; DM=DArT marker. ${ }^{\mathrm{c}}$ Shows absolute positions of test locations from left telomere in centiMorgans. ${ }^{\mathrm{d}}$ Variation explained by the QTL.

${ }^{\mathrm{e}}$ Shows source parents for the increasing allele. 
It was also observed that kernel number and kernel weight had highly significant positive correlation within themselves and with grain yield suggesting both of these traits could be equally important in breeding high-yielding sorghum cultivars. These two interdependent traits could be manipulated simultaneously or separately in selection of sorghum with high grain yield. However, kernel number was found to be influenced by planting time, while kernel weight was not. Our data showed that more kernels produced under early planting as compared to late planting. This result might be due to better opportunity of longer growing season under early plantings or smaller plant population size. When cold weather killed seedlings of several RI entries during early planting, we observed that the remaining seedlings use the opportunity of having more space to grow more profusely producing larger panicle and more kernels as we observed for SRN-39 parent also. The results indicated the importance of planting time for maximum kernel number. Contrary to kernel number, kernel weight seemed to be lightly affected by planting time. Based on Saeed et al. (1986), kernel weight might be affected more by moisture availability in the soil during critical period of grain filling rather than planting time. In present study, although less rainfall was received in the first year of our experiments as compared to the second year, there was no moisture stress that could affect grain fill or kernel weight at any time.

In addition to yield increase per unit area, yield stability across diverse growing environments is also an important consideration for plant breeders. In present study, both plant population and kernel number traits seemed to be unstable across environments. On contrary, grain yield and kernel weight seemed to be more stable. Based on its stability and high heritability, kernel weight might be one of the most important traits to attain stable grain yield in sorghum under diverse growing environments.

More stable grain yield could be obtained by late planting because optimum plant population can be established under late planting. However, in our study we found that late planted nurseries exhibited rapid growth rate, which could promote lodging during late seedling growth because of higher temperature. This again demonstrated the importance of optimal time of planting to attain optimum plant populations under early planting cold conditions. This can be realized with the development of sorghum cultivars with cold tolerance genes suited to early planting (Knoll \& Ejeta, 2008).

Although the extended growing time of present early planting did not seem to translate to higher overall mean grain yield, there were several individual entries that had higher grain yield under early planting, consistent with Knoll \& Ejeta (2008) observations for sorghum hybrids. The observation of extreme values (both minimum and maximum) under early cold planting was a recurring result for most of the traits measured in our study including panicle size and plant height (data not shown). This indicates both the challenges and the opportunities for sorghum genetic improvement under cold early planting.
4.2 QTL Analysis

Considering the quantitative nature of the traits in this study, divergence in the parents for most of the traits and performance of the RILs, surprisingly few QTL were detected in this study for each trait. However, in QTL analysis, several factors such as data quality, phenotypic performance, marker density, population size and growing environment can contribute to the power of QTL detection.

Considering data quality, obviously good quality data such as limited number of missing plot would be necessary to detect more QTL. In our study, missing plots were not more than three in our over 4600 plots and in general our data can be regarded as of a high quality. Other than limited number of missing plots, field agronomic performance by the genotype is also important to detect QTLs. The detections of more QTLs with our better performing nurseries might justify this assertion. However, from phenotypic data analysis, it was surprising that QTLs were detected rather in the least performing environment for kernel weight trait. It might be suggested that other data structures were also important in detection of more QTLs rather than mere phenotypic performance scored for kernel number. In addition, environment can affect the number of QTLs being detected. In some extreme cases, QTL may not even detect as for most traits in 2006 cold early planted nursery. Besides phenotypic data, genotypic (marker) data are an important issue in the power of QTL detection (Darvasi et al., 1993; Doerge et al., 1997; Doerge, 2002). In this study, relatively large and dense genetic map constructed from various markers was used. Our study confirms the utility of DArT marker system for sorghum as demonstrated in other most recent publications (Mace et al., 2008; Mace et al., 2009; Mace \& Jordan, 2011). Besides marker size, population size could affect the number of QTL detected (Beavis, 1994). In sorghum, Rami et al. (1998) detected no QTL with their limited population size. In our study, relatively large population size was utilized and to our knowledge, we deployed the largest $(N=528)$ RI lines population ever used to analyze QTL in sorghum.

From the above discussions, the few number of QTL detected in present analyses might be the actual number of QTL segregating in this population. The relatively high heritability values calculated for each trait and large LOD score particularly for grain yield trait in our study might give certain confidence in the number of QTLs detected. In our study, apart from our interest in the exploration of the number of QTLs expressed under contrasting environments, identification of QTLs associated with sorghum grain yield and its component traits deemed useful in breeding sorghum for higher grain yield.

As described in phenotypic data analyses, plant population is crucial in attaining high grain yield in sorghum and therefore, identification of robust QTLs associated with this trait is of particularly interest as previously addressed by Knoll \& Ejeta (2008). However, due to the fact that plant population develops 
early in the season when environmental conditions are less conducive for sorghum plant, QTLs associated with plant population size accessed through stand count at maturity are environmentally sensitive and may not be detected at all as in our 2006 experiments. Kernel number per panicle is also basically set during early growth as it is related to plant population (density). However, there is flexibility for sorghum plant to realize this trait more as a function of time in the growing season. This makes QTL associated with kernel number trait important for sorghum breeding aimed at higher grain yield. Regarding kernel weight, QTLs detected were few and limited to single environment in our study. However, when we decreased the QTL detection threshold LOD just slightly from the default 2.5 to 2.4, four more QTL were detected (data not shown) and these QTLs were consistent across planting dates (environments). These results might substantiate our findings in phenotypic data analysis and suggest the importance of kernel weight QTL in breeding sorghum for yield stability across diverse growing environments. In phenotypic data analysis, we observed the environment to have little impact on kernel weight as evidenced by small mean standard deviation and high heritability for this trait.

Consistent with the most quantitative nature of grain yield trait, the highest number of QTLs was detected for grain yield in our study despite little divergence in the parents for this trait. Rather many loci could contribute to the overall grain yield making breeding for grain yield a challenging task but from our finding, it is likely that one major QTL significantly contributed the greatest portion of grain yield as in oligogenic traits. Surprisingly our results showed that QTLs for grain yield were more stable across planting dates as in kernel weight. The results were consistent with the observations reported by Stuber et al. (1992) in corn. In our study, it might be speculated that the effect of environment on grain yield was buffered through physiological functions of the yield components since grain yield is rather the result of complex interaction of the individual components (Saeed et al., 1986).

In conclusion, our findings indicated that although grain yield trait is complex, one major QTL that significantly contribute to grain yield could be identified and utilized in breeding sorghum for higher grain yield. In addition, the robust SSR markers detected flanking grain yield and its component in our study could be used in breeding sorghum to improve grain yield under different planting conditions if validated with further research.

\section{Acknowledgments}

The financial support for this study was provided by the International Sorghum and Millets Research Network (INTSORMIL) of USAID.

\section{Conflict of Interest}

The authors declare that there is no conflict of interests that could possibly arise.

\section{References}

Basten CJ, Weir BS, Zeng Z-B (2005) QTL CARTOGRAPHER: A reference manual and tutorial for QTL mapping. Department of Statistics, North Carolina State University, Raleigh.

Beavis, WD (1994) The power and deceit of QTL experiments: Lessons from comparative QTL studies. In: Wilkinson DB (Ed.) Proceedings of the 49th Annual Corn and Sorghum Research Conference. American Seed Trade Association, Chicago, IL, USA, Pp. 250 - 266.

Bhattramakki, Dong DJ, Chhabra AK, Hart GE (2000) An integrated SSR and RFLP linkage map of Sorghum bicolor (L.) Moench. Genome 43: 988 -1002. doi: 10.1139/gen-43-6-988.

Borrell AK, Mullet JE, George-Jaeggli B, Oosterom EJVan, Hammer GL, Klein PE, Jordan DR (2014) Drought adaptation of stay-green sorghum is associated with canopy development, leaf anatomy, root growth, and water uptake. Journal of Experimental Botany 65: 6251 - 6262. doi: 10.1093/jxb/eru232.

Cisse ND, Ejeta G (2003) Genetic variation and relationships among seedling vigor traits in sorghum. Crop Science 43:824828. doi:10.2135/cropsci2003.8240.

Darvasi A, Weinreb A, Minke V, WellerJI, Soller M (1993) Detecting marker-QTL linkage and estimating QTL gene effect and map location using a saturated genetic map. Genetics 134 : $943-951$.

Doerge RW (2002) Mapping and analysis of quantitative trait loci in experimental populations. Nature Reviews Genetics 3:43-52. doi:10.1038/nrg703.

Doerge RW, Zeng ZB, Weir BS (1997) Statistical issues in the search for genes affecting quantitative traits in experimental populations. Statistical Science 12: 195 - 219. doi:10.1214/ss/1030037909.

Doggett H (1988): Sorghum (Second edition). John Wiley and Sons, New York, NY.

FAO (2012) Year Book (2012) Fishery and agriculture statistics. Rom, Italy.

Francis CA, Saeed M, Nelson LA, Roomaw R (1983) Yield stability of sorghum hybrids and random-mating population in early and late planting dates. Crop science 24: $1109-1112$.

Heinrich GM, Francis CA, Eastin JD, Saeed M (1985) Mechanisms of yield stability in sorghum. Crop Science 25: $1109-1112$. 100 DOI: 10.2135/cropsci1985.0011183X002500060050x. 
Knoll J, Ejeta G (2008) Marker-assisted selection for earlyseason cold tolerance in sorghum: QTL validation across populations and environments. Theoretical and Applied Genetics 116: 541 - 553. doi: 10.1007/s00122-007-0689-8.

Liu GF, Yang J, Xu HM, Hayat Y, Zhu J (2008) Genetic analysis of grain yield conditioned on its component traits in rice (Oryza sativa L.). Australian Journal of Agricultural Research 59: 189 - 195. http://dx.doi.org/10.1071/AR07163.

Lu G, Tang J, Yan J, Ma X, Li J, Chen S, Ma J, Liu Z, L. Zhu E, Zhang Y, Dai J (2006) Quantitative trait loci mapping of maize yield and its components under different water treatments at flowering time. Journal of Integrative Plant Biology 48: 1233 - 1243. doi: 10.1111/j.17447909.2006.00289.x.

Lu C, Shen L, Tan Z, Xu Y, He P, Chen Y, Zhu L (1997) Comparative mapping of QTLs for agronomic traits of rice across environments using a doubled haploid population. Theoretical and Applied Genetics 94: 1211 - 1217. doi: $10.1007 / \mathrm{s} 001220050393$.

Mace ES, Jordan DR (2011) Integrating sorghum whole genome sequence information with a compendium of sorghum QTL studies reveals uneven distribution of QTL and of generich regions with significant implication for crop improvement. Theoretical and Applied Genetics 123: 169 - 191. doi: 10.1007/s00122-011-1575-y.

Mace ES, Xia L, Jordan DR, Halloran K, Parh DK, Huttner E, Wenzl P, Kilian A (2008) DArT markers: Diversity analysis and mapping in Sorghum bicolor. BMC Genomics 9: 26. doi: 10.1186/1471-2164-9-26.

Mace ES, Rami JF, Bouchet S, Klein PE, Klein RR, Kilian A, Wenzl P, Xia L, Halloran K, Jordan DR (2009) A consensus genetic map of sorghum that integrates multiple component maps and high-throughput Diversity Array Technology (DArT) markers. BMC Plant Biology 9: 13 doi: 10.1186/1471-2229-9-13.

Phuong N, Stuzel H, Uptmoor R (2013) Quantitative trait loci associated to agronomic traits and yield components in a Sorghum bicolor L. Moench RIL population cultivated under pre-flowering drought and well-watered conditions. Journal of Agricultural Sciences $\quad 4:$ 781-791. http://dx.doi.org/10.4236/as.2013.412107.

Rami JF, Dufour P, Trouche G, Fliedel G, Mestres C, Davrieux F, Blanchard P, Hamon P (1998) Quantitative trait loci for grain quality, productivity, morphological and agronomical traits in sorghum (Sorghum bicolor L. Moench). Theoretical and Applied Genetics 97: 605 - 616. doi: 10.1007/s001220050936.
Saeed M, Francis CA, Clegg MD (1986) Yield component analysis in sorghum. Crop science 26: 346-351.

Saghai-Maroof MA, Soliman KM, Jorgense RA, Allard RW (1984) Ribosomal DNAspacer-length Polymorphisms in barley: Mendelian inheritance, chromosomal location and population dynamics. Proceedings of National Academy of Science USA 81:8014-8018.

Shehzad T, Okuno K (2015) QTL mapping for yield and yieldcontributing traits in sorghum (Sorghum bicolor (L.) Moench) with genome-based SSR markers. Euphytica 203:17 - 31. doi: 10.1007/s10681-014-1243-9.

Stickler FC, Pauli AW (1961) Influence of date of planting on yield and yield components in grain sorghum. Agronomy $\begin{array}{lllll}\text { Journal } & 53 \text { : } & 20 & - & 22 .\end{array}$ doi:10.2134/agronj1961.00021962005300010007x.

Stuber CW, Lincoln SE, Wolff DW, Helentjaris T, Lander ES (1992) Identification of genetic factors contributing to heterosis in hybrid form of elite maize inbred lines using molecular markers. Genetics 132: 823-839.

Tokatlidis IS, Koutroubas SD (2004) A review of maize hybrids' dependence on high plant population and its implications for crop yield stability. Field Crops Research 88: 103 - 114. doi:10.1016/j.fcr.2003.11.013.

Van Oijen AM (2006) Single-molecule studies of complex systems: the replisome. Molecular BioSystems. 3: 117-125 doi: 10.1039/b612545j.

Xue D, Zhou M, Zhang X, Chen S, Wei K, Zeng F, Mao Y, Wu F, Zhang G (2010) Identification of QTLs for yield and yield components of barley under different growth conditions. Journal of Zhejiang University Science B (Biomedicine and Biotechnology) 11 : 169 - 176. doi: 10.1631/jzus.B0900332.

Yu J, Tuinstra MR (2001) Genetic analysis of seedling growth under cold temperature stress in grain sorghum. Crop Science 41: 1438 - 1443. doi:10.2135/cropsci2001.4151438x.

Zeng ZB (1994) Precision mapping of quantitative trait loci. Genetics 136: 1457 - 1468.

Zou G, Zhai G, Feng Q, Yan S, Wang A, Zhao Q, Shao J, Zhang Z, Zou J, Han B, Tao Y (2012) Identification of QTLs for eight agronomically important traits using an ultrahighdensity map based on SNPs generated from high-throughput sequencing in sorghum under contrasting photoperiods. Journal of Experimental Botany Vol 63, Issue 15, 5451 - 5462. doi: $10.1093 / \mathrm{jxb} / \mathrm{ers} 205$. 